\title{
Prevalence and factors associated with suicidal ideation amongst college students in the Nelson Mandela Bay Municipality, South Africa
}

\begin{tabular}{|c|c|}
\hline \multicolumn{2}{|c|}{$\begin{array}{l}\text { Authors: } \\
\text { Adeyinka A. Alabi }{ }^{1,2} \text { (D) } \\
\text { Olawumi K. Oladimeji } \\
\text { Oladele V. Adeniyi } i^{4,5}\end{array}$} \\
\hline $\begin{array}{l}\text { Affiliations: } \\
{ }^{1} \text { Department } \\
\text { Medicine, Wa } \\
\text { University, Por } \\
\text { South Africa }\end{array}$ & $\begin{array}{l}\text { f Family } \\
\text { ter Sisulu } \\
\text { t Elizabeth, }\end{array}$ \\
\hline $\begin{array}{l}{ }^{2} \text { Department } \\
\text { Medicine, Dor } \\
\text { Provincial Hos } \\
\text { Elizabeth, Sou }\end{array}$ & $\begin{array}{l}\text { f Family } \\
\text { Nginza } \\
\text { oital, Port } \\
\text { h Africa }\end{array}$ \\
\hline $\begin{array}{l}{ }^{3} \text { Eastcape Mid } \\
\text { College, Uiten } \\
\text { South Africa }\end{array}$ & $\begin{array}{l}\text { ands TVET } \\
\text { nage, }\end{array}$ \\
\hline $\begin{array}{l}{ }^{4} \text { Department } \\
\text { Medicine, Wal } \\
\text { University, Eas } \\
\text { South Africa }\end{array}$ & $\begin{array}{l}\text { f Family } \\
\text { ter Sisulu } \\
\text { London, }\end{array}$ \\
\hline $\begin{array}{l}{ }^{5} \text { Department } \\
\text { Medicine, Cec } \\
\text { Hospital, East } \\
\text { South Africa }\end{array}$ & $\begin{array}{l}\text { f Family } \\
\text { lia Makiwane } \\
\text { ondon, }\end{array}$ \\
\hline $\begin{array}{l}\text { Correspondin } \\
\text { Adeyinka Alab } \\
\text { adeyinkaalabi }\end{array}$ & $\begin{array}{l}\text { author: } \\
\text { ayahoo.com }\end{array}$ \\
\hline $\begin{array}{l}\text { Dates: } \\
\text { Received: } 18 \mathrm{~J} \\
\text { Accepted: } 29 \mathrm{C} \\
\text { Published: } 29\end{array}$ & $\begin{array}{l}\text { ly } 2020 \\
\text { ct. } 2020 \\
\text { lan. } 2021\end{array}$ \\
\hline $\begin{array}{l}\text { How to cite th } \\
\text { Alabi AA, Oladi } \\
\text { Adeniyi OV. Pre } \\
\text { factors associa } \\
\text { suicidal ideatio } \\
\text { college studen } \\
\text { Mandela Bay } \\
\text { South Africa. S } \\
\text { Pract. 2021;63 } \\
\text { https://doi.org } \\
\text { v63i1.5195 }\end{array}$ & $\begin{array}{l}\text { is article: } \\
\text { meji OK, } \\
\text { valence and } \\
\text { ted with } \\
\text { n amongst } \\
\text { s in the Nelson } \\
\text { lunicipality, } \\
\text { Afr Fam } \\
\text { 1), a5195. } \\
\text { /10.4102/safp. }\end{array}$ \\
\hline Read online: & \\
\hline 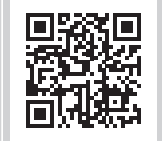 & $\begin{array}{l}\text { Scan this QR } \\
\text { code with your } \\
\text { smart phone or } \\
\text { mobile device } \\
\text { to read online. }\end{array}$ \\
\hline
\end{tabular}

Background: Suicidal behaviour amongst college students constitutes a significant social and public health problem globally. This study determined the prevalence and associated factors of suicidal ideation amongst students of higher education in the Nelson Mandela Bay Municipality (NMBM), South Africa.

Methods: In this institution-based cross-sectional study, a multistage cluster sampling of 826 participants, drawn from a college in NMBM, was conducted from January to March 2020. Data were collected with a standardised self-administered questionnaire. Multivariable logistic regression analysis was used to identify the factors associated with suicidal ideation.

Results: Participants' ages ranged from 18 to 24 years, with a mean age of 20.49 years (standard deviation, 1.88 years). The lifetime prevalence of suicidal ideation and plans in the preceding 12 months were $24.5 \%$ and $9.6 \%$, respectively. The odds of suicidal ideation were higher in students who experienced bullying (adjusted odds ratio [AOR], 1.89; 95\% confidence interval [CI], 1.35-2.65), mental illness (AOR, 1.89; 95\% CI, 1.35-2.65), a history of sexual assault (AOR, $2.50 ; 95 \% \mathrm{CI}, 1.20-5.21$ ) and experience of sexual assault by or to a close family member (AOR, $1.69 ; 95 \%$ CI, 1.01-2.82). Underlying chronic illness was associated with a twofold risk for suicidal ideation in both sexes.

Conclusion: About a quarter of the students sampled at the college had experienced suicidal ideation and some had had suicidal plans in the preceding 12 months. Screening for the identified risk factors amongst the student population coupled with prompt interventions would mitigate the risk of suicide in the study population.

Keywords: suicidal behaviour; suicidal plans; higher education; students; South Africa.

\section{Introduction}

Suicide constitutes a significant social and public problem globally, with one person dying by suicide every $40 \mathrm{~s}$ and many more people attempting suicide. ${ }^{1}$ Worldwide, suicide constitutes the second leading cause of death amongst people between the ages of 15 years and 29 years. ${ }^{2}$ It is also the second leading cause of death amongst college students in the United States of America. ${ }^{3}$ In South Africa, suicide is responsible for one out of every 10 unnatural deaths amongst young people, and many more engage in deliberate self-harm annually. ${ }^{4}$ There appears to be an increasing trend towards suicidal behaviour in the past 15 years, and this calls for preventative intervention. ${ }^{5}$

Suicidal behaviour encompasses suicidal ideation, deliberate self-harm and completed suicide. ${ }^{6}$ Suicidal ideation has been identified as an important precursor of completed suicides, and young people with suicidal ideation have a higher risk of committing suicide than those without ideation. ${ }^{7,8}$ Similarly, Montier et al. (2019) reported that about half of students with suicidal ideation transitioned to suicidal plans, whilst one-quarter progressed to suicide attempts. ${ }^{9}$ Therefore, timely identification of modifiable and non-modifiable risk factors for suicidal ideation should be part of intervention strategies to reduce deaths by suicide. With the World Health Organization's (WHO) 2020 deadline of the envisioned target of a 10\% reduction in suicide approaching, ${ }^{10}$ a clear understanding of the risk factors for suicidal ideation would assist in crafting institution-specific preventative strategies. 
Several studies conducted in both low- and high-income countries have reported an association between environmental, psychosocial, biological and behavioural factors and suicidal ideation amongst college students. ${ }^{11,12}$ Worldwide, mental illnesses such as depression, anxiety, personality disorders and bipolar disorders seem to be consistent risk factors for suicidal ideation amongst college students. ${ }^{13,14}$ College students are vulnerable to mental illness because of the stress of separation from their family support system, challenging academic load, financial constraint and peer pressure; such mental illnesses put them more at risk of suicidal ideation. ${ }^{15,16}$

In addition to primary mental illness, psychological trauma such as bullying, sexual assault, intimate partner violence and childhood adverse events appear to have a significant association with suicidal ideation. ${ }^{17,18,19,20}$ Previous studies have shown that a poor level of financial support, unemployment of parents and family instability are risk factors for suicidal ideation amongst students. ${ }^{21,22}$ Because of the dearth of published studies on suicidal ideation amongst students at institutions of higher learning in South Africa, it is unclear what the prevalence and risk factors for suicidal ideation are amongst such students in the country. Even more uncertain is the proportion of these students who transitioned to developing plans to commit suicide in the past year. These findings will assist higher education institutions' (HEIs) administrators in crafting appropriate interventions to mitigate the risk of suicide amongst the student population. This study determines the prevalence of suicidal ideation and plans amongst students of higher education in the Nelson Mandela Bay Municipality (NMBM), South Africa. In addition, the study further examines the factors associated with suicidal ideation in the cohort.

\section{Methods}

\section{Study design and setting}

This institution-based cross-sectional study was conducted between 15 January and 15 March 2020 at the Eastcape Midlands College, situated in NMBM, South Africa. Eastcape Midlands College, located in Uitenhage, has seven campuses and offers courses in Engineering, Business and occupational training programmes. A total number of 8563 students were registered for the 2019/2020 study sessions at all campuses. The distribution of students was as follows: Charles Goodyear Campus, 1308; High Street Campus, 673; Thanduxolo Campus, 904; Brickfields Road Campus, 416; Graaff-Reinet Campus, 807; Grahamstown Campus, 1677; Heath Park Campus, 1336; and Park Avenue Campus, 1442.

\section{Study population and sample size estimation}

All students in the various programmes and stated year of study at the Eastcape Midlands College in NMBM were eligible for the study. Participants were included if they had registered for the 2019/2020 academic year, were at least 18 years old at the time of the study and were willing to complete a 15-min questionnaire. However, participants who were clinically unwell were excluded from the study. In order to ensure that the findings would be generalisable to the entire student population, a sample size of 902 was calculated by using the formula for cross-sectional studies:

$\mathrm{N}=\mathrm{PQ} \times 4 / 0.02^{2}$

[Eqn 1]

where $\mathrm{P}$ is the expected prevalence of students with suicidal ideation ( $\mathrm{P}$ was set as $9.1 \%$ as reported by a South African study ${ }^{23}$ for an error risk of 0.05 ), and $Q=1-P$. An initial total of 827 participants was calculated; then an additional 75 participants were added to bring the total to 902, in anticipation of incomplete responses on the main outcome measure (suicidal ideation and plans) from the students.

\section{Sampling technique}

The study adopted a multistage cluster random sampling technique in selecting the participants. Out of seven campuses, we randomly selected four campuses (Thanduxolo, Charles Goodyear, Heath Park and Park Avenue), and each campus was clustered into lecture rooms/classes. For inclusiveness, participants were stratified based on the years and campuses of study. The second sampling involved random selection of classes from the clusters at each of the selected campus, and all the students who were present in the selected classes were invited to participate in this study voluntarily. Recruitment of participants corresponded with the sizes of clusters, campus and year of study. Four trained research assistants distributed the questionnaire to be self-administered.

\section{Intervention for participants}

In line with the principle of beneficence, participants who self-reported suicidal ideation and plans were referred for full psychological assessment at the nearest hospital in the NMBM or at any private institution of their choice. Furthermore, the research assistants had debriefing sessions during the course of the study.

\section{Measures \\ Outcome variable}

The main outcome for this study was the occurrence of suicidal ideation and plans. Suicidal ideation was measured by asking the participants if they had ever experienced suicidal thoughts in their lives. Furthermore, suicidal plans were assessed by asking the participants if they had planned to kill themselves in the preceding 12 months. Binary responses of 'yes' or 'no' were coded as $1=$ yes and $2=$ no.

\section{Independent variables}

The independent variables were selected based on the existing literature. They were divided into sections, where the first one captured the demographic characteristics of the participants (age, gender, primary language and year of study). Section 2 comprised questions that explored the potential drivers of suicidal ideation: socio-economic, clinical factors (chronic illnesses, substance use) and academic status. Section 3 explored the predisposing factors to suicidal ideation and 
planning. The experience of being bullied was assessed by asking, 'Have you ever been bullied by another student in any manner?' Economic status was assessed by obtaining information about the employment status of parents, total monthly family income and the number of household members. Bursary and other student loans were excluded because most of the college students were bursary recipients. The socio-economic status of the participants was assessed by the occupational status of one or both parents, the total household income and the number of household members, the self-rating of financial support and the rating of meeting of financial obligations by the participants.

Participants were also asked to rate their perceptions of their financial support from being very poor to very good. Relationship status and experience of abuse were also explored with rating questions. The presence of chronic illnesses was explored through a number of yes/no questions (yes $=1$, no $=2$ ). Relationship status with a partner and satisfaction were assessed and coded. Perception of body image was evaluated by asking the participant, 'How would you describe your body weight?' The expected responses included 'underweight', 'normal weight', 'overweight' or 'obese'. Participants' perception of their physical appearance was also assessed by asking, 'How do you feel about your physical appearance?' Probable responses included 'I feel perfect', 'moderately good' or 'bad'.

Section 4 explored suicidal ideation and plans with four questions: (1) 'In the past month, did you think that you would be better off dead or wish you were dead?' (2) 'In the past 12 months, did you think about harming yourself with the intention of killing yourself?' (3) 'In the past 12 months, did you ever seriously think of taking your life?' (4) 'In the past 12 months, have you made any plan to kill yourself?'

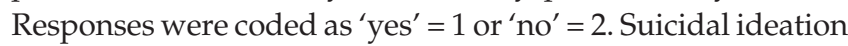
was defined as responding 'yes' to any of the questions. Chronic illness was assessed by asking the participants if they had been diagnosed by a health professional with any of the following chronic illnesses: chronic pain, human immunodeficiency virus (HIV), depression, anxiety, bipolar disorder, schizophrenia or unknown chronic illness. Their responses were coded as 1 for 'no' and 2 for 'yes'.

In order to ascertain the validity of the questionnaire, a pilot study was conducted with 10 students from one of the schools. Minor adjustments were made after reviewing the responses as well as feedback from the participants in the pilot study. The results of the pilot study were not included in the main study.

\section{Data analysis}

The responses of participants were coded and entered into Epi Info version 3.5.3 software. Data analysis was performed using STATA software version 15.0 (Stata Corporation, College Station, TX, US). Descriptive analyses (frequencies, percentage and standard deviations) were used to describe the sociodemographic characteristics and to estimate the prevalence of suicidal ideation and planning. The chi-square test and bivariate analysis were used to assess the associations between suicidal ideation and independent variables. Multiple logistic regression analysis was fitted to assess the effect of independent variables on suicidal ideation, after adjusting for probable confounding variables. Variables that were significant at the $p<0.05$ level were reported for factors associated with suicidal ideation. The associations were measured using odds ratios (ORs) and 95\% confidence intervals (95\% CIs).

\section{Ethical consideration}

Ethical approval was obtained from the Walter Sisulu University's Ethics Committee (reference no. 038/2019), and permission was obtained from the Department of Health (reference no. EC_201912005). In addition, permission was obtained from the management of the selected campuses prior to the implementation of the study protocol. The participants gave written informed consent demonstrating their willingness to voluntarily participate in the study. There was no financial inducement for participation. Furthermore, each participant received an information leaflet detailing the purpose and process of the study. The right to privacy and confidentiality of medical information was respected during and after the study. All research processes followed the Helsinki Declaration and laid out ethical procedures.

\section{Results}

A total of 902 questionnaires were administered, but only 855 participants returned the questionnaires, thus giving a response rate of $94.8 \%$. Of the returned questionnaires, 29 were incomplete and therefore were excluded from the final analysis, owing to missing information about suicidal ideation. Of these, 19 were female responses and 10 were those of males.

\section{Demographic characteristics of the participants}

A total sample of 826 was included in the final analysis, 509 women (61.6\%) and 317 men (38.4\%). Overall, Charles Goodyear Campus had 323 respondents (37.8\%), High Street Campus had 242 respondents (28.3\%), Thanduxolo Campus had 137 respondents (16\%), Park Avenue Campus had 135 respondents (15.8\%) and 18 respondents $(2.1 \%)$ did not indicate their campus. Furthermore, the largest number of respondents (382) were in their first year of study $(44.7 \%)$, followed by year $2(n=286 ; 33.4 \%)$ and lastly, year $3(n=187 ; 21.9 \%)$.

Table 1 displays the descriptive statistics of the participants. The ages of the participants ranged from 18 to 24 years with a mean age of 20.49 years (SD, 1.88). The majority of the participants were from urban communities $(70.6 \%)$, had never used cannabis (79.2\%), reported having used alcohol (74.4\%) and had no underlying chronic illnesses (75.2\%). Chronic pain, HIV, depression, anxiety, bipolar disorder and 
TABLE 1: Background characteristics of respondents stratified by sex.

\begin{tabular}{|c|c|c|c|c|c|c|}
\hline \multirow[t]{2}{*}{ Variables } & \multicolumn{2}{|c|}{ Male } & \multicolumn{2}{|c|}{ Female } & \multicolumn{2}{|c|}{$\begin{array}{c}\text { All } \\
\text { participants }\end{array}$} \\
\hline & $n$ & $\%$ & $n$ & $\%$ & $n$ & $\%$ \\
\hline All respondents & 317 & 38.4 & 509 & 61.6 & 826 & 100.0 \\
\hline \multicolumn{7}{|l|}{ Family structure } \\
\hline Single parent & 130 & 41.0 & 240 & 47.2 & 370 & 44.7 \\
\hline Both parents & 149 & 47.0 & 204 & 40.1 & 353 & 42.7 \\
\hline Foster parents & 38 & 12.0 & 65 & 12.8 & 103 & 12.5 \\
\hline \multicolumn{7}{|l|}{ Parents' occupation } \\
\hline Both employed & 68 & 21.5 & 81 & 15.9 & 149 & 18 \\
\hline One employed & 124 & 39.1 & 220 & 43.2 & 344 & 41.6 \\
\hline Non-employed & 125 & 39.4 & 208 & 40.9 & 333 & 40.3 \\
\hline \multicolumn{7}{|l|}{ Place of residence } \\
\hline Rural & 102 & 32.2 & 142 & 27.9 & 244 & 29.5 \\
\hline Urban & 215 & 67.8 & 367 & 72.1 & 582 & 70.5 \\
\hline \multicolumn{7}{|l|}{ Rate family financial support } \\
\hline Very poor & 21 & 6.6 & 48 & 9.4 & 69 & 8.4 \\
\hline Poor & 44 & 13.9 & 98 & 19.3 & 142 & 17.2 \\
\hline Moderate & 140 & 44.2 & 182 & 35.8 & 322 & 39 \\
\hline Good & 77 & 24.3 & 114 & 22.4 & 191 & 23.1 \\
\hline Very good & 35 & 11.0 & 67 & 13.2 & 102 & 12.3 \\
\hline \multicolumn{7}{|l|}{ Have all needs met } \\
\hline Yes & 144 & 45.4 & 227 & 44.6 & 371 & 44.9 \\
\hline No & 173 & 54.6 & 282 & 55.4 & 455 & 55.1 \\
\hline \multicolumn{7}{|l|}{ Alcohol use } \\
\hline Used alcohol in the last 30 days & 164 & 51.7 & 234 & 46 & 398 & 48.2 \\
\hline Used alcohol before the last 30 days & 74 & 23.3 & 142 & 27.9 & 216 & 26.2 \\
\hline Never used alcohol & 79 & 24.9 & 133 & 26.1 & 212 & 25.7 \\
\hline \multicolumn{7}{|l|}{ Use cannabis } \\
\hline Yes & 93 & 29.3 & 79 & 15.5 & 172 & 20.8 \\
\hline No & 224 & 70.7 & 430 & 84.5 & 654 & 79.2 \\
\hline \multicolumn{7}{|l|}{ Have underlying medical conditions } \\
\hline Yes & 66 & 20.8 & 139 & 27.3 & 205 & 24.8 \\
\hline No & 251 & 79.2 & 370 & 72.7 & 621 & 75.2 \\
\hline \multicolumn{7}{|l|}{ Experienced education failures } \\
\hline Yes & 106 & 39.8 & 160 & 31.4 & 266 & 32.2 \\
\hline No & 211 & 66.6 & 349 & 68.6 & 560 & 67.8 \\
\hline \multicolumn{7}{|l|}{ Experienced sexual abuse } \\
\hline I am a survivor & 11 & 3.5 & 42 & 8.3 & 53 & 6.4 \\
\hline Someone close is a survivor & 27 & 8.5 & 98 & 19.3 & 125 & 15.1 \\
\hline I have never experienced sexual abuse & 279 & 88.0 & 369 & 56.9 & 648 & 78.5 \\
\hline \multicolumn{7}{|l|}{ Experienced unintended pregnancy } \\
\hline Yes & 24 & 7.6 & 57 & 11.2 & 81 & 9.8 \\
\hline No & 293 & 92.4 & 452 & 88.8 & 45 & 90.2 \\
\hline \multicolumn{7}{|l|}{ Conflictual relationship } \\
\hline Yes & 69 & 21.8 & 141 & 27.7 & 210 & 25.4 \\
\hline No & 248 & 78.2 & 368 & 72.3 & 616 & 74.6 \\
\hline \multicolumn{7}{|l|}{ Body weight perceptions } \\
\hline Normal & 246 & 77.6 & 367 & 71.1 & 613 & 74.2 \\
\hline Abnormal & 71 & 22.4 & 142 & 27.9 & 213 & 25.8 \\
\hline \multicolumn{7}{|l|}{ Feel your life is better off than friends } \\
\hline Yes & 150 & 47.3 & 202 & 39.7 & 352 & 42.6 \\
\hline No & 167 & 52.7 & 307 & 60.3 & 474 & 57.4 \\
\hline
\end{tabular}

schizophrenia were reported by $10.9 \%, 3.5 \%, 11.0 \%, 6.4 \%$, $1.8 \%$ and $0.2 \%$ of the sample, respectively (Table 1 ).

More participants were from single-parent families (44.8\%) compared to two-parent families (42.7\%). More female participants $(47.2 \%)$ came from single-parent homes in comparison to male participants $(41.0 \%)$. Only $27.2 \%$ of the participants perceived that their financial needs were met by
TABLE 2: Multiple logistic regression model analysis showing factors associated with suicidal ideation.

\begin{tabular}{|c|c|c|c|c|c|c|}
\hline \multirow[t]{2}{*}{ Variable } & \multicolumn{2}{|c|}{$\begin{array}{l}\text { Suicidal } \\
\text { ideation }\end{array}$} & \multicolumn{2}{|c|}{ Unadjusted } & \multicolumn{2}{|c|}{ Adjusted } \\
\hline & $n$ & $\%$ & OR & $95 \% \mathrm{Cl}$ & OR & $95 \% \mathrm{Cl}$ \\
\hline \multicolumn{7}{|l|}{ Age } \\
\hline $16-19$ & 87 & 32.2 & 0.89 & $0.66-1.22$ & 1.10 & $0.77-1.58$ \\
\hline $20-24$ & 193 & 34.7 & 1 & - & 1 & - \\
\hline \multicolumn{7}{|l|}{ Sex } \\
\hline Male & 75 & 23.7 & 0.46 & $0.34-0.63 * *$ & 0.54 & $0.39-0.77 *$ \\
\hline Female & 205 & 40.3 & 1 & - & 1 & - \\
\hline \multicolumn{7}{|l|}{ Experienced bullying } \\
\hline Yes & 143 & 46.7 & 2.45 & $1.82-3.30 * *$ & 1.89 & $1.35-2.65 * *$ \\
\hline No & 137 & 26.3 & - & - & 1 & - \\
\hline \multicolumn{7}{|c|}{ Ever experienced unplanned pregnancy } \\
\hline Yes & 37 & 45.7 & 1.74 & $1.09-2.76^{*}$ & 1.38 & $0.81-2.33$ \\
\hline No & 243 & 32.6 & - & - & 1 & - \\
\hline \multicolumn{7}{|c|}{ Experienced education failure } \\
\hline Yes & 105 & 39.5 & 1.44 & $1.06-1.94 *$ & 1.37 & $0.97-1.92$ \\
\hline No & 175 & 31.3 & - & - & 1 & - \\
\hline \multicolumn{7}{|c|}{ Feel better off that friends } \\
\hline Yes & 84 & 23.9 & 0.45 & $0.33-0.60^{* *}$ & 0.64 & $0.45-0.90 *$ \\
\hline No & 196 & 41.4 & - & - & 1 & - \\
\hline \multicolumn{7}{|c|}{ Have underlying medical conditions } \\
\hline Yes & 109 & 61.1 & 2.99 & $2.16-4.14 * *$ & 2.12 & $1.47-3.05^{* *}$ \\
\hline No & 171 & 27.5 & - & - & 1 & - \\
\hline \multicolumn{7}{|l|}{ Relationship conflicts } \\
\hline Yes & 92 & 43.8 & 1.78 & $1.29-2.45 * *$ & 1.24 & $0.85-1.80$ \\
\hline No & 188 & 30.5 & 1 & - & 1 & - \\
\hline \multicolumn{7}{|l|}{ Body weight perception } \\
\hline Not normal & 104 & 48.8 & 2.37 & $1.72-3.27^{* *}$ & 1.65 & $1.15-2.37 *$ \\
\hline Normal & 176 & 28.7 & 1 & - & 1 & - \\
\hline \multicolumn{7}{|c|}{ Feeling about body appearance } \\
\hline Perfect & 94 & 25.5 & 0.28 & $0.17-0.46 * *$ & 0.46 & $0.26-0.79 *$ \\
\hline Moderate & 140 & 37.4 & 0.49 & $0.31-0.80 *$ & 0.57 & $0.34-0.98 *$ \\
\hline Bad & 46 & 54.8 & 1 & - & 1 & - \\
\hline \multicolumn{7}{|l|}{ All needs met } \\
\hline Yes & 101 & 27.2 & 0.58 & $0.43-0.78 * *$ & 0.76 & $0.53-1.08$ \\
\hline No & 179 & 39.3 & - & - & 1 & - \\
\hline \multicolumn{7}{|l|}{ Family financial support } \\
\hline Poor & 92 & 43.6 & 1.86 & $1.29-2.70^{*}$ & 1.15 & $0.74-1.78$ \\
\hline Moderate & 102 & 31.7 & 1.12 & $0.79-1.57$ & 0.96 & $0.65-1.42$ \\
\hline Good & 86 & 29.4 & 1 & - & 1 & - \\
\hline \multicolumn{7}{|c|}{ Experienced sexual abuse } \\
\hline I am a survivor & 33 & 62.3 & 4.23 & $2.36-7.56^{* *}$ & 2.08 & $1.10-3.94 *$ \\
\hline Someone very close is & 65 & 52.0 & 2.77 & $1.88-4.10 * *$ & 1.79 & $1.15-2.78^{*}$ \\
\hline $\begin{array}{l}\text { Never experienced } \\
\text { sexual abuse }\end{array}$ & 182 & 28.1 & 1 & - & 1 & - \\
\hline
\end{tabular}

the family. Overall, $32.2 \%$ of the participants had experienced educational failures. The proportion of participants, who reported conflictual relationships, unwanted pregnancy and sexual abuse, was $25.4 \%, 9.8 \%$ and $6.4 \%$, respectively. About a quarter of the participants perceived that they had abnormal body weight, and more than half of all the participants felt that they were not better off than their friends.

\section{Prevalence of suicidal ideations and plan}

The lifetime prevalence of suicidal ideation was $24.5 \%$, with significant gender variation (Figure 1). Significantly, more 


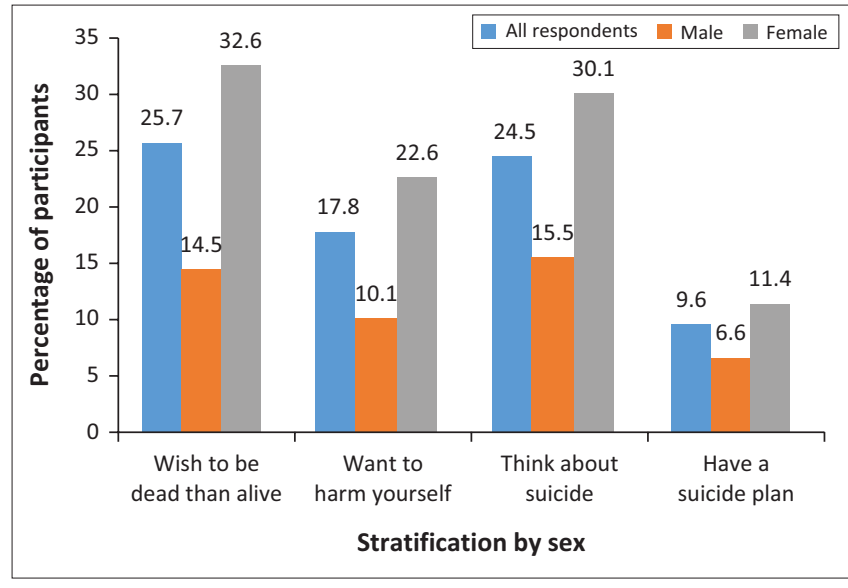

FIGURE 1: Proportion of respondents having suicidal ideation stratified by sex. women than men reported lifetime suicidal ideation (30.1\% vs. $15.5 \%)$. Amongst all the participants with suicidal ideations ( $n=79), 9.6 \%$ had planned to commit suicide in the preceding 12 months. The lifetime prevalence of suicidal plan was $11.4 \%$ amongst women and $6.6 \%$ amongst men.

\section{Factors associated with suicidal ideation (multiple logistic regression analysis)}

In the crude and adjusted multiple logistic model analysis (Table 2), male sex, feeling better off financially than friends, moderate or perfect feeling about body appearance, and having all needs met were associated with lower odds of experiencing suicidal ideation. The magnitude and direction of association between these factors and suicidal ideation

TABLE 3: Multiple logistic regression model analysis showing factors associated with suicidal ideation amongst males and females.

\begin{tabular}{|c|c|c|c|c|c|c|c|c|}
\hline \multirow[t]{3}{*}{ Variable } & \multicolumn{4}{|c|}{ Males } & \multicolumn{4}{|c|}{ Females } \\
\hline & \multicolumn{2}{|c|}{ Unadjusted } & \multicolumn{2}{|c|}{ Adjusted } & \multicolumn{2}{|c|}{ Unadjusted } & \multicolumn{2}{|c|}{ Adjusted } \\
\hline & OR & $95 \% \mathrm{Cl}$ & OR & $95 \% \mathrm{Cl}$ & OR & $95 \% \mathrm{Cl}$ & OR & $95 \% \mathrm{Cl}$ \\
\hline \multicolumn{9}{|l|}{ Age } \\
\hline $16-19$ & 0.84 & $0.48-1.48$ & 1.02 & $0.52-2.00$ & 0.91 & $0.62-1.32$ & 1.11 & $0.72-1.72$ \\
\hline $20-24$ & 1 & - & 1 & - & 1 & - & 1 & - \\
\hline \multicolumn{9}{|l|}{ Experienced bullying } \\
\hline Yes & 2.50 & $1.47-4.24 *$ & 1.74 & $0.95-3.19$ & 2.52 & $1.74-3.65 * *$ & 2.01 & $1.32-3.06 * *$ \\
\hline No & 1 & - & 1 & - & - & - & 1 & - \\
\hline \multicolumn{9}{|c|}{ Ever experienced unplanned pregnancy } \\
\hline Yes & 1.08 & $0.41-2.83$ & 0.88 & $0.28-2.70$ & 1.91 & $1.09-3.32 *$ & 1.44 & $0.77-2.70$ \\
\hline No & 1 & - & 1 & - & - & - & 1 & - \\
\hline \multicolumn{9}{|l|}{ Experienced educational failure } \\
\hline Yes & 2.27 & $1.33-3.86^{*}$ & 1.79 & $0.96-3.33$ & 1.19 & $0.81-1.74$ & 1.20 & $0.79-1.84$ \\
\hline No & 1 & - & 1 & - & 1 & - & 1 & \\
\hline \multicolumn{9}{|l|}{ Feel better off than friends } \\
\hline Yes & 2.68 & $1.49-4.81 * *$ & 1.00 & $0.54-1.85$ & 3.01 & $2.02-4.51 * *$ & 0.51 & $0.33-0.78^{*}$ \\
\hline No & 1 & - & 1 & - & 1 & - & 1 & - \\
\hline \multicolumn{9}{|l|}{ Have underlying medical conditions } \\
\hline Yes & 2.68 & $1.49-4.81$ & 2.24 & $1.11-4.51 *$ & 3.01 & $2.02-4.51 * * *$ & 2.14 & $1.37-3.33^{*}$ \\
\hline No & 1 & - & 1 & - & 1 & - & 1 & - \\
\hline \multicolumn{9}{|l|}{ Relationship conflicts } \\
\hline Yes & 1.30 & $0.71-2.39$ & 1.17 & $0.58-2.34$ & 1.91 & $1.30-2.84$ & 1.37 & $0.87-2.17$ \\
\hline No & 1 & - & 1 & - & 1 & - & 1 & - \\
\hline \multicolumn{9}{|l|}{ Body weight perception } \\
\hline Not normal & 2.76 & $1.56-4.89 * *$ & 2.22 & $1.14-4.33 *$ & 2.13 & $1.43-3.15 * *$ & 1.54 & $0.98-2.42$ \\
\hline Normal & 1 & - & 1 & - & 1 & - & 1 & - \\
\hline \multicolumn{9}{|l|}{ Feeling about body appearance } \\
\hline Perfect & 0.09 & $0.04-0.23 * *$ & 0.10 & $0.04-0.28 * *$ & 0.50 & $0.28-0.91 *$ & 0.90 & $0.46-1.77$ \\
\hline Moderate & 0.30 & $0.13-0.71^{*}$ & 0.30 & $0.11-0.77 *$ & 0.63 & $0.35-1.12$ & 0.75 & $0.39-1.43$ \\
\hline Bad & 1 & - & 1 & - & 1 & - & 1 & - \\
\hline \multicolumn{9}{|l|}{ All needs met } \\
\hline Yes & 0.70 & $0.41-1.18$ & 0.71 & $0.38-1.33$ & 0.52 & $0.36-0.75 * *$ & 0.69 & $0.45-1.08$ \\
\hline No & 1 & - & 1 & - & - & - & 1 & - \\
\hline \multicolumn{9}{|l|}{ Family financial support } \\
\hline Poor & 1.66 & $0.84-3.29$ & 1.41 & $0.62-3.21$ & 1.86 & $1.19-2.91 *$ & 1.04 & $0.61-1.79$ \\
\hline Moderate & 0.91 & $0.50-1.66$ & 0.99 & $0.48-2.03$ & 1.32 & $0.86-2.02$ & 1.00 & $0.62-1.63$ \\
\hline Good & - & - & 1 & - & 1 & - & 1 & - \\
\hline \multicolumn{9}{|l|}{ Experienced sexual abuse } \\
\hline I am a survivor & 3.18 & $0.94-10.77$ & 0.84 & $0.19-3.79$ & 3.95 & $2.01-7.78 * *$ & 2.50 & $1.20-5.21 *$ \\
\hline Some very close is a survivor & 3.05 & $1.35-6.87^{*}$ & 2.12 & $0.82-5.52$ & 2.33 & $1.48-3.66 * *$ & 1.69 & $1.01-2.82^{*}$ \\
\hline Never experienced sexual abuse & 1 & - & 1 & - & 1 & - & 1 & - \\
\hline
\end{tabular}

$\mathrm{OR}$, odds ratio; $\mathrm{Cl}$, confidence interval.

$*, p<0.05 ; * *, p<0.01 ; * * *, p<0.001$. 
remained after adjusting for confounding variables, except for having all needs met.

Furthermore, having experienced bullying, unplanned pregnancy or failure in education, having underlying chronic medical conditions, having relationship conflicts, abnormal body weight perceptions, having poor family financial support and experience of sexual abuse or experience of sexual assault by/to someone very close were significantly associated with higher odds of having suicidal ideation. After adjusting for confounding variables, some of these factors (ever having experienced unplanned pregnancy or educational failure, having relationship conflicts, having all needs met and poor family financial support) were no longer significant.

\section{Gender variations in the factors associated with suicidal ideation (multiple logistic regression analysis)}

In the crude multiple logistic model analysis (Table 3), experience of bullying, experience of educational failure, feeling better off than friends and someone very close having experienced sexual abuse were all significantly associated with suicidal ideation amongst male participants. However, after adjusting for covariates, all these factors became insignificant. Having underlying chronic illness and abnormal perception of body weight were associated with higher odds of suicidal ideation; having a moderate to perfect feeling about their appearance was associated with lower odds of suicidal ideation amongst the male participants. The magnitude and direction of association remained the same after adjustment in the logistic regression model analysis.

Furthermore, the experience of being bullied, having underlying chronic illness, being a survivor of sexual abuse and having someone very close who had experienced sexual abuse were associated with higher odds of suicidal ideation amongst female participants. Although having poor family financial support, abnormal body weight perception, having experienced education failures, relationship conflicts and ever having experienced an unplanned pregnancy were associated with suicidal ideation amongst female participants, these factors all became insignificant after adjusting for other variables, using logistic regression model analysis.

\section{Discussion}

Given the increasing trend of suicide and suicide attempts amongst students at HEIs of learning globally and in South Africa, this study sought to assess the rate of suicidal ideation, plans and influencing factors of suicidal ideation disaggregated by gender of students at an HEI in NMBM in South Africa. This study found a high prevalence of suicidal ideation (24.5\%) amongst the students of this school. A previous South African study reported a similar prevalence of $25.4 \%$ amongst first-year university students. ${ }^{24}$ Other studies in Africa reported similar prevalence amongst college students (26.9\% in Tunisia ${ }^{25}$ and 25.5\% in Mozambique ${ }^{26}$ ). However, a lower prevalence of $13.5 \%$ was reported amongst college students in the United States of America. ${ }^{27}$ This finding was lower than the prevalence reported amongst Ethiopian university students, with lifetime prevalence of suicidal ideation and plans of $58.3 \%$ and $37.3 \%$, respectively..$^{28}$ The variations in the prevalence of suicidal ideation in different countries could be attributed to differences in sociocultural factors and the prevailing economic climate of those studies. In the present study, it should be noted that the students were experiencing a period of unrest (student protest) because of diminished financial support from their funders. ${ }^{29}$ Perhaps the financial hardship of the students contributed to the high prevalence observed in the study population.

The prevalence of suicidal plans was 9.6\%, with females more likely to have suicidal plans than males. This finding was lower than the prevalence reported in another South African study, with a prevalence of suicidal plan of $12.6 \%$ in the preceding 12 months amongst the secondary school students. ${ }^{30}$ A plausible explanation for the observed lower prevalence of suicidal plans in our study in comparison to the study by Guedria-Tekari et al. ${ }^{25}$ could be the level of maturity or difference in age of the participants. In the current study, our participants were older and had attained post-secondary education, in comparison to the adolescents and high school students in the other study. More studies are needed in the sub-Saharan African region to elucidate the prevalence of suicidal plans amongst scholars. This information will provide insight for the Association of African Universities/Colleges on which to base regional policy on suicidal ideation and plans amongst students of higher learning.

Our study shows that more women than men reported lifetime suicidal ideations $(30.1 \%$ vs. $15.5 \%)$. This finding corroborates previous reports from China ${ }^{31}$ and Mozambique. ${ }^{32}$ A possible explanation for this finding could be the higher occurrence of the significant risk factors of suicidal ideation such as experiences of sexual abuse, which are higher amongst female participants $(8.3 \%$ vs. $3.5 \%)$. The psychological impact of sexual abuse is probably similar in both genders; however, the number of reported incidents of male sexual abuse experienced in our study was too small to make any significant deductions.

In this study, students who had experienced bullying, especially female students, had higher odds of suicidal ideation. These findings are in agreement with previous studies, which reported victims of bullying being at higher risk of suicidal behaviour. ${ }^{18,26,33}$ The increased suicide risk may be attributed to untoward sequelae of bullying, which include depression, anxiety, substance abuse and the feeling of not belonging. ${ }^{26}$ School authorities could potentially screen for experiences of bullying and its behavioural complications in order to mitigate suicidal ideation at HEIs. 
This study also found that having underlying chronic illnesses was significantly associated with suicidal ideation, with a higher risk amongst those with two or more chronic diseases. This finding is consistent with the results of previous studies. ${ }^{34,35}$ A Canadian study reported a higher prevalence of suicidal ideation amongst people with chronic diseases, and the risk increased with the number of comorbidities. ${ }^{34}$ Similarly, Ferro et al.${ }^{35}$ reported a higher risk of suicidal ideations amongst patients with mental illness. It is plausible that many students did not have access to clinical support and care. This is evidenced by the fact that there are shortages of psychologists on many of the college campuses. Similarly, the shortages of psychologists are a critical challenge within the public sector's healthcare facilities. This finding has significant implications for planning of interventions directed toward managing underlying chronic illnesses, including mental illness, amongst students of HEIs in the region. Furthermore, this finding highlights the urgency of incorporating screening for chronic illnesses, including mental illness and suicidal ideation, during school registrations.

Given the high HIV prevalence $(7.9 \%)^{32}$ in the age group of 15-24 years, included in this study, it should be noted that only 25 students reported a diagnosis of HIV in this cohort (3\%). Hence, this finding should be treated with caution because of the possibility of under-reporting of HIV status by the participants. Sexual assault increased the risk of suicidal ideation, whether through personal experience or that of someone very close to them. Some previous studies have reported similar findings. ${ }^{36,37}$ The increased odds of suicidal ideation amongst rape survivors have been attributed to the cascade of emotional response that follows the traumatic experience, from self-blame to depression and post-traumatic stress disorder. ${ }^{6}$

Participants' perception of abnormal body weight was associated with increased odds of suicidal ideation. This is more true for males compared to females. Similarly, participants who felt that their body appearance was moderate to perfect had lower odds of suicidal ideation, especially amongst the male students. This finding is consistent with results from previous studies that reported that underweight males and males with normal weight but body weight dissatisfaction were most vulnerable to suicidal ideation. ${ }^{38,39}$ Similarly, a study conducted amongst adolescents in China showed that only males with the perception of underweight or obesity were at higher risk of suicidal ideation. ${ }^{39}$ On the contrary, Shin et al. ${ }^{40}$ in Korea reported that only women with distorted perceptions of body weight were more likely to express suicidal ideation than those who perceived a normal body image. The present study highlights the need to pay attention to body perceptions amongst young male students with a view to promptly recognising suicidal tendencies in them.

In our study, cannabis and alcohol usage in the preceding 12 months did not show any significant association with having suicidal ideations. This finding is contrary to what has been reported in previous studies, in which alcohol and cannabis use were significantly associated with suicidal

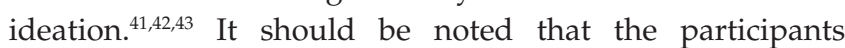
included in our study were younger (18-24 years) in comparison to other studies (ages up to 60 years) that reported this association. . $^{41,42,43}$. Furthermore, we did not quantify the intensity of alcohol use in our study.

\section{Strength and limitations}

This is the first study to report the prevalence of suicidal ideation and plans in any HEI in the Eastern Cape Province, South Africa. In addition, this study adopted multistage cluster random sampling of a representative (large) sample of students in the selected institution. This study therefore provides a reliable data baseline for the school authority, the Department of Higher Education and other relevant stakeholders in the province and country to craft policy on screening for suicidal ideation.

However, the limitations of the study cannot be ignored. The cross-sectional nature of the study precludes causal association between the risk factors and suicidal ideation. Self-reported lifestyle behaviours and underlying mental and chronic medical conditions may have been underreported. Although the investigators anonymised the data collection instrument in order to limit the effect of social desirability bias, under-reporting of medical and mental illnesses may have occurred. Lastly, we did not capture the anthropometric measurements of the participants to determine their body mass index; therefore, we could not draw any conclusions as to whether their perception of their body weight was an accurate or distorted concern.

\section{Conclusion}

We report a high prevalence of suicidal ideations and plans amongst students of higher education in the NMBM, Eastern Cape, with significant gender variations in the influencing factors. The study further demonstrated a significant association between suicidal ideation and gender, bullying experience, having underlying mental illness, having had a sexual assault experience and perception of body image. The various stakeholders of the college should consider implementing a screening strategy towards identifying the risk factors as well as suicidal ideation, with prompt interventions for the students.

\section{Acknowledgements}

The authors wish to acknowledge the students and the campus managers of the Eastcape Midlands Technical and Vocational Education and Training (TVET) College, Uitenhage, South Africa.

\section{Competing interests}

The authors have declared that no competing interests exist. 


\section{Authors' contributions}

A.A.A. and O.K.O. conceptualised, designed and implemented the study protocol. A.A.A. and O.V.A. guided the data analysis and drafted the manuscript. All authors read and approved the final draft for submission.

\section{Funding information}

A.A.A. received financial support from the Discovery Health Foundation, South Africa, towards the implementation of this study.

\section{Data availability statement}

The questionnaires and data collected are safely stored and are available upon request.

\section{Disclaimer}

The views and opinions expressed in this article are those of the authors and do not necessarily reflect the official policy or position of any affiliated agency of the authors.

\section{References}

1. World Health Organization (WHO). Suicide data [homepage on the Internet]. [cited 2020 Feb 08]. Available from: http://www.who.int/mental_health/prevention/ suicide/suicideprevent/en

2. WHO. Preventing suicide: A global imperative [homepage on the Internet] Luxembourg: World Health Organization; 2014 [cited 2020 Feb 09]. Available from: https://apps.who.int/iris/bitstream/handle/10665/131056/978924 1564779-ger.pdf

3. Lamis DA, Lester DE. Understanding and preventing college student suicide. Springfield, IL: Charles C Thomas Publisher; 2011.

4. Schlebusch L. Suicide prevention: A proposed national strategy for South Africa. Afr J Psychiatr. 2012;15(6):436-440. https://doi.org/10.4314/ajpsy. v15i6.56

5. South African Depression and Anxiety Group (SADAG). South African Depression and Anxiety Group. [cited 2020 Feb 08]. Available from: http:// www.sadag.org

6. Sigurvinsdottir R, Ullman SE, Canetto SS. Self-blame, psychological distress, and suicidality among African American female sexual assault survivors. Traumatology. 2020;26(1):1-10. https://doi.org/10.1037/trm0000195

7. Gili-Planas M, Roca-Bennasar M, Ferrer-Perez V, Bernardo-Arroyo M. Suicidal ideation, psychiatric disorder, and medical illness in a community epidemiological study. Suicide Life Threat Behav. 2001;31(2):207-213. https://doi.org/10.1521/ suli.31.2.207.21508

8. Groleger U, Tomori M, Kocmur M. Suicidal ideation in adolescence-an Indicator of actual risk? Israel J Psychiatry Relat Sci. 2003;40(3):202.

9. Mortier P, Auerbach RP, Alonso J, et al. Suicidal thoughts and behaviors among first-year college students: Results from the WMH-ICS project. J Am Acad Child Adolesc Psychiatr. 2018;57(4):263.e1-273.e1.

10. WHO. Mental health action plan 2012 - 2020 [homepage on the Internet] Geneva; 2013 [cited 2020 May 06]. Available from: https://apps.who.int/iris/ bitstream/handle/10665/89966/9789241506021_eng.pdf

11. Pandey AR, Bista B, Dhungana RR, Aryal KK, Chalise B, Dhimal M. Factors associated with suicidal ideation and suicidal attempts among adolescent students in Nepal: Findings from global school-based students health survey. PLoS One. 2019;14(4):e0210383. https://doi.org/10.1371/journal.pone. 0210383

12. Wang M, Kou C, Bai W, et al. Prevalence and correlates of suicidal ideation among college students: A mental health survey in Jilin Province, China. J Affect Disord. 2019;246:166-173. https://doi.org/10.1016/j.jad.2018.12.055

13. Bantjes JR, Kagee A, McGowan T, Steel H. Symptoms of posttraumatic stress, depression, and anxiety as predictors of suicidal ideation among South African university students. J Am Coll Health. 2016;64(6):429-437. https://doi.org/10.10 university students. J Am Coll

14. Nguyen DT, Wright EP, Dedding C, Pham TT, Bunders J. Low self-esteem and its association with anxiety, depression, and suicidal ideation in Vietnamese secondary school students: A cross-sectional study. Front Psychiatr. 2019;10:698 https://doi.org/10.3389/fpsyt.2019.00698
15. Vaez M, Ponce de Leon A, Laflamme M. Health-related determinants of perceived quality of life: A comparison between first-year university students and their working peers. Work [serial online]. 2006 [cited 2020 May 06];26:167-117. working peers. Work [serial online].

16. Verger P, Guagliardo V, Gilbert F, Rouillon F, Kovess-Masfety V. Psychiatric disorders in students in six French universities: 12-month prevalence, comorbidity, impairment, and help-seeking. Soc Psychiatry Psychiatr Epidemiol [serial online] 2010 [cited 2020 May 07];45:189-199. Available from: https://goo.gl/nCVZRj

17. Wang GF, Han AZ, Zhang GB, et al. Sensitive periods for the effect of bullying victimization on suicidal behaviors among university students in China: The roles of timing and chronicity. J Affect Disord. 2020;268:12-19. https://doi.org/ 10.1016/j.jad.2020.02.049

18. Baiden P, Kuuire VZ, Shrestha N, Tonui BC, Dako-Gyeke M, Peters KK. Bullying victimization as a predictor of suicidal ideation and suicide attempt among senior high school students in Ghana: Results from the 2012 Ghana Global School-Based Health Survey. J Sch Violence. 2019;18(2):300-317. https://doi.org/10.1080/153 88220.2018.1486200

19. Keefe KM, Hetzel-Riggin MD, Sunami N. The mediating roles of hostility and dissociation in the relationship between sexual assault and suicidal thinking in college students. J Interpers Violence. 2020;35(7-8):1635-1653. https://doi.org/ $10.1177 / 0886260517698282$

20. Kim J, Son S. Relationship between adverse childhood experiences and the risk of lifetime suicide attempts. Korean J Child Stud. 2020;41(2):27-39. https://doi. org/10.5723/kjcs.2020.41.2.27

21. Yildiz M, Demirhan E, Gurbuz S. Contextual socioeconomic disadvantage and adolescent suicide attempts: A multilevel investigation. J Youth Adolesc. 2019;48(4):802-814. https://doi.org/10.1007/s10964-018-0961-z

22. Currier $D$, Patton $G$, Sanci $L$, et al. Socioeconomic disadvantage, mental health and substance use in young men in emerging adulthood. Behav Med. 2019 Jun;26: 1-9. https://doi.org/10.1080/08964289.2019.1622504

23. Joe $S$, Stein DJ, Seedat S, Herman A, Williams DR. Prevalence and correlates of non-fatal suicidal behaviour among South Africans. Br J Psychiatr. 2008;192(4): 310-311. https://doi.org/10.1192/bjp.bp.107.037697

24. Bantjes J, Lochner C, Saal W, et al. Prevalence and sociodemographic correlates of common mental disorders among first-year university students in postapartheid South Africa: Implications for a public mental health approach to apartheid South Africa: Implications for a public mental health approach to
student wellness. BMC Publ Health. 2019;19(1):922. https://doi.org/10.1186/ s12889-019-7218-y

25. Guedria-Tekari A, Missaoui S, Kalai W, Gaddour N, Gaha L. Suicidal ideation and suicide attempts among Tunisian adolescents: Prevalence and associated factors. Pan Afr Med J. 2019;34:105. https://doi.org/10.11604/pamj.2019.34. 105.19920

26. Peng $Z$, Klomek AB, Li L, et al. Associations between Chinese adolescents subjected to traditional and cyber bullying and suicidal ideation, self-harm and suicide attempts. BMC Psychiatry. 2019;19(1):324. https://doi.org/10.1186/ suicide attempts.
s12888-019-2319-9

27. Bandy R, Hudgens-Wallace S, Francis D, Pope R. Mental health issues are associated with increased risky health behaviors among US college students [homepage on the Internet]. Oral Presentation. 2020. [cited 2020 May 07]. Available from: https://kb.gcsu.edu/src/2020/oral_presentations/10

28. Abdu Z, Hajure M, Desalegn D. Suicidal behavior and associated factors among students in Mettu University, South West Ethiopia, 2019: An institutional based cross-sectional study. Psychol Res Behav Manag. 2020;13:233. https://doi.org/ cross-sectional study. Psych
10.2147/PRBM.S240827

29. Mkhuseli Sizani: Unpaid NSFAS fees lead to lockdown [homepage on the Internet]. [cited 2020 Mar 14]. Available from: https://webcache.googleusercontent.com/ search?q=cache:cq21ygh W6sJ:https://www.dailysun.co.za/News/unpaid-nsfassearch?q=cache:cq21ygh_W6sJ:https://www.dailysun.co.
fees-lead-to-lockdown-20200312-2;Dailysun.co.za/News

30. Khuzwayo N, Taylor M, Connolly C. High risk of suicide among high-school learners in uMgungundlovu District, KwaZulu-Natal Province, South Africa. S Afr Med J. 2018;108(6):517-523. https://doi.org/10.7196/SAMJ.2018.v108i6. 12843

31. Zhang YY, Lei YT, Song Y, Lu RR, Duan JL, Prochaska JJ. Gender differences in suicidal ideation and health-risk behaviors among high school students in Beijing, China. J Glob Health. 2019;9(1):010604. https://doi.org/10.7189/ jogh.09.010604

32. Pengpid S, Peltzer K. Suicide attempt and associated factors among in-schoo adolescents in Mozambique. J Psychol Af. 2020;30(2):130-134. https://doi.org/1 $0.1080 / 14330237.2020 .1746569$

33. Messias E, Kindrick K, Castro J. School bullying, cyberbullying, or both: Correlates of teen suicidality in the 2011 CDC Youth Risk Behavior Survey. Compr Psychiatr. 2014;55(5):1063. https://doi.org/10.1016/j.comppsych.2014. 02.005

34. Dai H, Mei Z, An A, Wu J. Epidemiology of physical and mental comorbidity in Canada and implications for health-related quality of life, suicidal ideation, and healthcare utilization: A nationwide cross-sectional study. I Affect Disord. 2020;263:209-215. https://doi.org/10.1016/j.jad.2019.11.146

35. Ferro MA, Rhodes AE, Kimber M, et al. Suicidal behaviour among adolescents and young adults with self-reported chronic illness. Can J Psychiatry. 2017;62(12) 845-853. https://doi.org/10.1177/0706743717727242

36. Newins AR, Glenn JJ, Wilson LC, et al. Psychological outcomes following sexual assault: Differences by sexual assault setting. Psychol Serv. 2020. https://doi. org/10.1037/ser0000426

37. Ullman S, Brecklin L. Sexual assault and suicidal behavior in the National Comorbidity Survey. Suicide Life Threat Behav. 2002;32:117-130. https://doi. org/10.1521/suli.32.2.117.24398 
38. Lee CG, Seo D-C. Trajectory of suicidal ideation in relation to perceived overweight from adolescence to young adulthood in a representative United States sample. J Adolesc Health. 2013;53(6):712-716. https://doi.org/10.1016/j. jadohealth.2013.06.013

39. Kim D-S. Body image dissatisfaction as an important contributor to suicidal ideation in Korean adolescents: Gender difference and mediation of parent and peer relationships. J Psychosom Res. 2009;66(4):297-303. https://doi.org/10.1016/j. jpsychores.2008.08.005

40. Shin J, Choi Y, Han K-T, et al. The combined effect of subjective body image and body mass index (distorted body weight perception) on suicidal ideation. J Prev Med Public Health. 2015;48(2):94. https://doi.org/10.3961/jpmph.14.055
41. Halladay JE, Munn C, Boyle M, Jack SM, Georgiades K. Temporal changes in the cross-sectional associations between Cannabis use, suicidal ideation, and depression in a nationally representative sample of Canadian adults in 2012 compared to 2002. Can J Psychiatry. 2020;65(2):115-123. https://doi.org/ $10.1177 / 0706743719854071$

42. Sher L. Alcoholism and suicidal behavior: A clinical overview. Acta Psychiatr Scand. 2006;113(1):13-22. https://doi.org/10.1111/j.1600-0447.2005.00643.x

43. Borges G, Benjet C, Orozco R, Medina-Mora M-E, Menendez D. Alcohol, cannabis and other drugs and subsequent suicide ideation and attempt among young Mexicans. J Psychiatr Res. 2017;91:74-82. https://doi.org/10.1016/j.jpsychires. 2017.02.025 